\title{
Sectoral Estimates of Informality: A New Method and An Application to Turkish Economy
}

\author{
Running Head: Sectoral Estimates of Informality in Turkey
}

\begin{abstract}
In this paper we use results of a novel survey covering 1000 firms from 16 different sec- tors of Turkish economy along with a two-sector general equilibrium model to measure the extent of informality in these sectors. Moreover, we also evaluate effects of two different policy tools, namely level of income taxes and tax enforcement on informality. Our results show that while both are effective policy tools in dealing with informal- ity, enforcement is a relatively more efficient tool and tax becomes quite ineffective especially at low levels of informality.
\end{abstract}

JEL codes:: E26; H26; O17; O41

Keywords: informal sector; firm-level data, two-sector general equilibrium model. 


\section{Introduction}

In this study, using a survey conducted with a sample covering 1000 representative firms in Turkey, we measure the extent of informality in 16 different sectors of Turkish economy. Using information from the survey, we calibrate a two-sector general equilibrium model to back out the extent of informal economic activities in these sectors. In the model, firms choose to operate either in the formal or the informal sector after comparing potential maximised profits from each sector. The government exogenously imposes a tax on profits of formal firms to finance its spending, which can only be partially enforced on informal firms. Once we characterise the model, we use the survey data to calibrate the model, to construct sectoral measures of informality and then to conduct and evaluate effects of several policy experiments.

Informality constitutes a big obstacle for many economies and governments, especially in the developing countries where the average informal economy size is estimated to be about $35 \%$ of the official GDP (See Buehn and Schneider, 2012 or Elgin and Oztunali, 2012.) Schneider and Enste (2000) as well as Schneider (2005) defines informality as "...all economic activities that contribute to the officially calculated (or observed) gross national product but are currently unregistered." Examples of this are firms that evade paying taxes for their business activities or employ workers without (or partially) paying for their social security benefits. Another paper by Ihrig and Moe (2004) defines informal economy as a sector which produces legal goods, but does not comply with government regulations. As expected, informality poses serious economic, social and political problems for an economy. A large informal economy hinders governments' efforts to collect enough revenue, harming efficient provision of public goods and services, as well as reducing total productivity; thereby reducing the growth potential of an economy. On the other hand, informal sector also provides a room for firms and household to at least 
partially avoid distortionary government taxation and regulation. It also offers employment opportunities for highly unproductive and unskilled labor that could not otherwise find any job opportunities in the formal sector and therefore would be unemployed if the informal sector were not present.

Although informality is an ubiquitous phenomenon all around the world, the determinants of it are yet to be agreed upon by economists. Even though various ideas were thrown into focus, including but not limited to the relationship between informality and tax burden, tax enforcement, institutional quality and various other economic, political and social factors ${ }^{1}$ many issues about its nature and consequences still remain largely under-explored or unresolved. (Schneider, 2005) For example, the evidence presented in the existing literature on informality, has failed to generate a consensus around the measurement of the informal sector among researchers. Several macro or micro approaches have been suggested to provide measures of ${ }^{2}$ informality; however these methodologies are generally not fit to obtain sectoral measures. In this regard, the contribution of our study is two-fold: First, we use a two-sector dynamic general equilibrium model and combine it with a specific firm-level survey data covering 16 different sectors and 1000 firms in Turkey. This allows us to obtain sectoral estimates ${ }^{3}$ of the informality. Second, we use the model to investigate effects of several policy tools and report the response of informality to changes in these tools. Even though we only apply our model to the Turkish economy, provided that we have firm-level survey data includ-

\footnotetext{
'See Schneider (2005), Levy (2008), La Porta and Shleifer (2008, 2014), Buehn and Schneider (2012), Besley and Persson (2013) among many others.

${ }^{2}$ Buehn and Schneider (2012) and Elgin and Oztunali (2012) provide an excellent review of the different methodologies used to measure extent of informal economic activity.

${ }^{3}$ Many governments construct sectoral estimates of informality as part of their GDP statistics. These are usually based on the share of sector output estimated to be undertaken according to traditional as opposed to modern technologies. However, the true share of informality, either aggregate or by sector, cannot be known, nor can any estimate be compared to it. The implications for size of different definitions can be explored, but the real issues regarding informality concern the micro foundations of productivity and growth, where size is mainly an indicator of the potential magnitude of these underlying issues. However, the main aim and contribution of this paper is not to explore these micro foundations or determinants and effects of informality, instead develop a novel size estimation approach that combines survey results with a micro-founded model.
} 
ing the required variables of the model, without loss of generality it can be applied to any national economy.

In the literature, there are a few studies using firm-level data or firmlevel models to understand firm behaviour with respect to informality. Most of these studies follow the size distribution idea of Lucas (1978) in which 'managerial talent' is the determinant of the size of a firm. This managerial talent manifests itself as productivity parameter, i.e. shows the unexplained part in converting factor inputs into output. Rauch (1991) had the lead in this regard and in this study firms are allowed to pay lower wages if they are small, in other words enforcement is only applied to firms bigger than a certain size, which in turn creates a dichotomy between formal and informal firms, namely small ones operate in the informal sector while large ones choose to be formal. Fortin et al. (1997) adds wage and evasion dualisms to the size dualism to check for the impact of taxation and wage controls. The result they reach is that in the equilibrium informal firms have the opportunity of paying smaller wages and evading taxes but there is a risk of getting caught and punished for operating informally. They test their theoretical findings using data from Cameroon. Moreover, Amaral and Quintin (2006) develops a competitive model of the labor market in which they use the Lucas framework of managerial talent. Being in the formal sector brings the benefit of capital availability and a tax burden. The equilibrium shows that large firms operate formally. Also the informal sector mainly employs low skilled workers and an employee gets the same wage in both formal and informal sectors, meaning that there is only one labor market. De Paula and Scheinkman (2009) uses the Lucas method to investigate the determinants of informality in Brazil. They introduce lower interest rates and taxes on sales for the formal sector although the wages are the same for both formal and informal sectors. They similarly find that smaller firms operate informally and then test this finding by using a survey conducted in Brazil. Another related study is the one by 
Cerda and Saravia (2013), where the authors try to add informal sector to an optimal taxation environment. Finally, Galiani and Weinschelbaum (2011) develops a similar model in which they try to account for three facts: the size dualism, skill dualism (low-skilled workers work in the informal sector) and a new one which states that working family members other than the household head generally work in the informal sector. On the empirical side Benjamin and Nbaye (2012) investigate the productivity differences among formal and informal firms by using data for 900 businesses in Benin, Burkina Faso and Senegal and find that formal firms exhibit higher productivity levels compared to informal firms. Similar studies have been conducted by Byiers (2009),Taymaz (2009) as well as various others. However, contrary to our study, none of these studies use firm-level survey findings to calibrate a general equilibrium model and obtain informality estimates for different sectors or economies. This aims to be the main contribution of our paper.

The rest of the paper proceeds as follows: In the next section we present several facts on informality in the Turkish economy. Next, in the third section we introduce our model and present its characterization. Then in the fourth section we present the calibration and simulation of the model, sector informality estimates as well as the policy experiments. Finally, in the last section we provide some concluding remarks and a discussion.

\section{Informality in Turkish Economy}

According to the aggregate estimates reported in Elgin and Oztunali (2012) or Buehn and Schneider (2012) ${ }^{4}$, Turkey, along with Mexico, has one of the two largest informal sectors (as \% of GDP) among OECD member economies. Figure 1 below documents the evolution of informal sector size as \% of GDP in

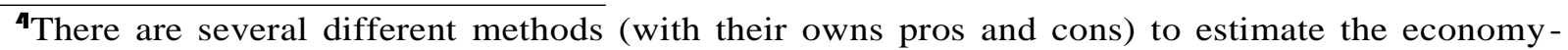
wide aggregate size of the informal economy in the literature but the two prevailing with most citations from the literature ones are the MIMIC method used by Buehn and Schneider (2012) or the dynamic general equilibrium model developed by Elgin and Oztunali (2012)
} 
Turkey using both MIMIC and DGE estimates as well as the GDP-weighted average of OECD member economies. The figure reveals that Turkish informal sector has declined sharply from 1980s onwards; however is still significantly larger than the OECD average ${ }^{5}$. Moreover, according to a report by OECD (2008) over $40 \%$ of the labor force in the Turkish economy is either working in informal salaried jobs or as own-account or unpaid family workers. While fully informal employment is concentrated mainly in small businesses, partial informality, in the form of under-declaration of earnings, is common even in larger businesses.

Mostly due to the lack of data sectoral studies of Turkish informal economy are almost non-existent and the existing ones are generally focused on the supply side of the labor market. ${ }^{6}$ Even though there are a number of micro level studies conducted in different countries ${ }^{7}$, most of the few existing

\footnotetext{
${ }^{5}$ See Elgin (2012) for other estimates of informal sector size for the Turkish economy from the existing literature on the Turkish economy

${ }^{6}$ Tansel (1999), Tansel (2001), Savasan and Schneider (2006), Taymaz (2009), Acar and Tansel (2012a, 2012b), Acar and Tansel (2014) and Balkan and Tumen (2014) are among the examples.

${ }^{7}$ Maloney (1999), Pisani and Pagan (2004), Bucheli and Ceni (2010), Kaplan, Piedro and Seira (2011), and more recently Cantekin and Elgin (2016) are among the examples.
} 
studies on Turkish informal economy generally deal with the issue of estimating the aggregate size of it and its sectoral and microeconomic characteristics are highly under-investigated. Among the few existing studies on the Turkish informal sector, Cantekin and Elgin (2016) deserve a relatively longer discussion as it uses the very same dataset as in the current paper. Using the same firm-level survey covering 1000 firms from the Turkish economy, Cantekin and Elgin (2016) provide a measure for both the prevalence and growth effects of informality in Turkey. Entirely based on the responses given by the owners and managers of the firm, the authors conduct a complete characterization of several firm characteristics and provide information on the extent of informality as well as its effects on various economic outcomes of these firms. They find that the aggregate level of informality originating from the firm-level data is in the range of 27 to 30 $\%$ of GDP. Moreover, the cross-sectional econometric analysis they conduct using the survey data shows that there is an inverted-U relationship between specific measures of informality and growth expectations of firms. (both based on responses of firm representatives) That is, growth expectations of firms are small with lower and higher levels of informality and high with medium levels of informality. This result implies that informality does not necessarily and directly act as a barrier for growth perceptions, at least in a linear way. This is an important result for emerging markets and developing economies that generally do have a significantly large informal sector. In this respect, economic policy should be designed taking into account that informality is not necessarily a barrier for growth. Such a policy design might manifest itself as an increase in the toleration for at least some informal economic activities or should at least take into account how a reduction in informality would affect economic growth depending on the nature of the non-linearity of the relationship between these two variables.

On top of the findings of Cantekin and Elgin (2016), the goal of the current paper is twofold: First, it aims to develop a universal methodology that can be 
used to any economy (provided that the necessary data is available) to impute (rather than entirely estimate it using survey responses) sectoral informality estimates. Second, utilizing an already existing sectoral firm-level dataset we apply this methodology to the Turkish economy, present and characterize the findings.

\section{Model}

In what follows we present a two-sector dynamic general equilibrium model involving heterogeneity in firms as well as sectoral choice.

\subsection{Firms}

There is a set I of mass one heterogenous firms indexed by $\mathrm{i}$ that produce a single good. Heterogeneity comes from the aforementioned Lucas (1978) framework in which the managerial ability (or the productivity parameter) $A_{i t}$ differs across firms.

There are two types of production technologies available to firms: the first type uses capital and labor as inputs and the other one employs only labor. The first type of technology is available for formal firms and the profit from this is taxed at the rate of $T$, where ( $T \quad[0,1])$, whereas the second type of technology is available to informal firms. When the informal technology is chosen, the firm faces a probability of detection by the government which depends on the government's level of tax enforcement as well as the number of workers the firm employs. Enforcement is represented by the parameter $\rho$, where ${ }^{8}(\rho \quad[0,1])$. Likewise, the employee size is represented through a function $\lambda(I)$ and this function shows that possibility of evasion from taxes

\footnotetext{
8. Similar to Ihrig and Moe (2004), we can interpret $\rho$ in one of two ways: First, it can be interpreted as a probability of being caught by tax inspectors and when caught the informal firm is expected to pay a rate equal to $T$. Alternatively, if the government imposes an additional penalty on informal firms (when they are caught) $\rho T$ can incorporate both the tax rate and the penalty rate discounted by the probability of getting caught by the government.
} 
decreases as firm's number of employees increases, which is intuitively plausible as the larger the firm gets in size, the easier for it to get noticed and caught when conducting informal economic activity.

We assume that the output of a firm in the formal sector is given by $A_{i t} f\left(k_{i t}, l_{i t}\right)$, whereas the output of a form in the informal sector is $A_{i t} g\left(l_{i t}\right)$. Both production functions are of decreasing returns to scale ${ }^{9}$, strictly increasing, strictly concave and satisfy Inada conditions. Firms rent capital from households at the rate of $r_{t}$, and pay $w_{i t}$ as wage to the workers of the formal sector and $w_{i t}{ }^{\text {inf }}$ to the ones of the informal sector. Therefore the profit functions can be written as follows:

Formal Profits:

$$
V_{i}=\max (1-\tau)\left[A_{i t} f\left(k_{i t}, l_{i t}\right)-r_{i t} k_{i t}-w_{i t} l_{i t}\right]
$$

Informal Profits:

$$
V_{i}^{\text {inf }}=\max \left(1-\rho \lambda\left(l_{i t}\right) r\right)\left[A_{i t} g\left(l_{i t}\right)-w_{i t}^{i n f} l_{i t}\right]
$$

Each firm, depending on its productivity/managerial talent, chooses the sector ${ }^{10}$ in which it is going to operate by comparing the maximized profits that they would get from each sector. Then, the firm will solve the following dichotomy:

$$
\max \left\{V_{i t}, V_{i t}^{\text {inf }}\right\}
$$

\section{Proposition 1. There exists a threshold productivity/managerial talent level}

\footnotetext{
${ }^{9}$ This assumption is necessary so that the firms end up with positive maximized profits in both sectors.

${ }^{10}$ Actually, no firm is totally informal as even highly informal firms pay some taxes or fees to local author- ities, pay some (for example value-added) taxes for their inputs or are registered to some local chamber or government authority. However, our model uses a shortcut to classify firms within the formal and informal sector. Our main purpose is not to exactly find out whether a firm is fully formal or informal. Instead we are after finding average informality size in a sector.
} 
$A_{i}^{*}$ in which the firm shifts into the other sector ${ }^{11}$ such that:

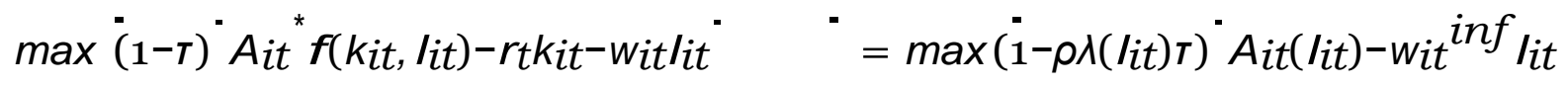

Proof. The results follows immediately when we insert the profit maximis- ing firstorder conditions back to the profit equations and then compare the profits of both sectors.

Corollary 1. A firm's capital or labor demand depends on which sector it is operating in. Therefore, we have:

$$
k_{i t}=0 \quad \text { if } \quad A_{i t} \leq A_{t}^{*}
$$

If we assume that markets are competitive then capital and labor will be paid at their marginal productivities, which are given by the following:

$$
\begin{gathered}
r_{t}=A_{i t} f_{k}\left(k_{i t}, l_{i t}\right) \\
w_{t}=A_{i t f l}\left(k_{i t}, l_{i t}\right) \\
\text { м } \left.^{i n f}=A_{i t g l(l i t} l_{i n f}\right)
\end{gathered}
$$

Moreover, the aggregate factor demands are the sum of individual demands. Hence:

$$
\begin{aligned}
& K_{t}^{D}=\int_{A_{t}^{*}}^{\infty} \mathrm{k}_{\mathrm{it}} \mathrm{dG}\left(\mathrm{A}_{\mathrm{it}}\right) \\
& L_{t}^{D}=\int_{A_{t}^{*}}^{\infty} \mathrm{l}_{\mathrm{it}} \mathrm{dG}\left(\mathrm{A}_{\mathrm{it}}\right) \\
& L_{t}^{D, \text { inf }}=l_{\mathrm{it}}^{\mathrm{inf}} G\left(A_{t}^{*}\right)
\end{aligned}
$$

\footnotetext{
I ISurely, one can come up with counterexamples of highly efficient informal firms and inefficient formal firms at the firm-level data. However, there are several findings in the literature that on average at the firm-level informal firms tend to be less productive and at the aggregate level, a larger informal sector is associated with lower level of productivity; such as Djankov et al. (2003), Straub (2005), Dabla-Norris et al. (2005), Amaral and Quintin (2006), Perry et al. (2007), Taymaz (2009), Busso, Fazio and Levy (2012) and more recently La Porta and Shleifer (2014).
} 


\subsection{Households}

We have an infinitely lived representative household maximising over consumption $\left\{c_{t}\right\}_{t=0}^{\infty}$ and leisure $\left\{h_{t}\right\}_{t=0}^{\infty}$

$$
\sum_{i=0}^{\infty} \beta U\left(c_{t}, h_{t}\right)
$$

subject to the following constraints:

$$
\begin{gathered}
c_{t}+i_{t}+\frac{b_{t+1}^{d}}{R_{t}}=r_{t} K_{\mathrm{t}}+w_{t} L_{t}+w_{t}^{\mathrm{inf}} L_{t}^{i n f}+b_{t}^{d} \\
+\int_{A_{i}^{*}}^{\infty} \mathrm{V}_{\mathrm{it}} \mathrm{dG}\left(\mathrm{A}_{\mathrm{it}}\right)+V_{\mathrm{it}}^{\mathrm{inf}} G\left(A_{t}^{*}\right) \\
K_{t+1}=i_{t}+(1-\delta) K_{t} \\
h_{t}+L_{t}+L_{t}^{\text {inf }}=\bar{H}
\end{gathered}
$$

Equation (3) is the budget constraint, equation (4) describes the capital accumulation and finally the last equation is the time-constraint, where $\bar{H}>0$ is the total time available to the stand-in household.

We assume that the utility function $U$ (.) is strictly increasing and strictly concave. Initially, at period o, the household has a capital stock of $K_{0}>0$ and a government bond stock of $b_{0}$. Each period, the household chooses his consumption, leisure, investment and bond holdings. $\delta$ is the assumed depreciation rate. The household rents his capital $K_{t}$ for a rental rate of $r_{t}$ and his labor for a wage of $w_{t}$ if he works in the formal sector and $w_{t}^{\text {inf }}$ if he works in the informal sector. The last two arguments in equation (3) are the (after-tax) profits received by the household from the formal sector firm and 
the informal sector firm respectively. $R_{t}$ is the interest rate for the stock of bonds $b_{t}^{d}$.

\subsection{Government}

The government in this model has an exogenous stream of expenditures which we define as $\left\{e_{t}\right\}_{t=0}^{\infty}$. The government only imposes tax on profits. However, we assume that its only revenue source is not the profits received from the formal firms but also the income received through punishments applied to the detected informal firms. Here, we assume that the government commits to the policies it builds. The government's budget constraint is therefore given by the following:

\subsection{Equilibrium}

We can define the competitive equilibrium for this economy as follows:

Definition 1. Given an enforcement level $\rho$, a competitive equilibrium is sequences of allocations $\left\{c_{t}, k_{i t}, l_{i t}, l_{i t}^{\text {inf }}, b_{t}\right\}_{t=0}^{\infty}$, prices $\left\{r_{t}, w_{t}, w_{t}^{\text {inf }}, R_{t}\right\}_{t=0}^{\infty}$, government policy $\left\{\tau_{t}, e_{t}\right\}_{t=0}^{\infty}$ and threshold productivity/managerial talent $\left\{A_{t}^{*}\right\}_{t=0}^{\infty}$ such that:

1. Sequences $\left\{c_{t}, k_{i t}, l_{\text {it }}, l_{i t}^{\text {inf }}, b_{t}\right\}_{t=0}^{\infty}$ solve the household's problem given by the equations (11)-(14).

2. Each firm solves firm's problem (equation 1), given $A_{\text {it }}$ :

3. $\left\{A_{t}{ }^{*}\right\}_{t=0}^{\infty}$ is determined through the Theorem 1.

4. The sequences $\left\{\tau_{t}, e_{t}\right\}_{t=0}^{\infty}$ make the government budget constraint (6) hold every period 
5. Capital, labor, bond and goods markets clear

$$
\begin{gathered}
K_{t}=\int_{A_{t}}^{\infty} \mathrm{k}_{\mathrm{it}} \mathrm{dG}\left(\mathrm{A}_{\mathrm{it}}\right) \\
L_{t}=\int_{A_{t}{ }^{*}}^{\infty} \mathrm{l}_{\mathrm{it}} \mathrm{dG}\left(\mathrm{A}_{\mathrm{it}}\right) \\
L_{t}{ }^{\mathrm{inf}}=l_{\mathrm{it}^{i n f}}{ }^{\text {inf }}\left(A_{t}{ }^{*}\right) \\
h_{t}+L_{t}+L_{t}{ }^{\text {inf }}=\bar{H} \\
b_{t}{ }^{s}=b_{t}{ }^{d}
\end{gathered}
$$

and

$$
c_{t}+e_{t}+K_{t+1}=\int_{A_{i}^{*}}^{\infty} A_{i t} f\left(k_{\text {it }}, l_{i t}\right) d G\left(A_{i t}\right)+A_{i t} g\left(l_{i t}^{\text {inf }}\right) G\left(A_{t}^{*}\right)+(1-\delta) K_{t}
$$

\section{Empirical Analysis}

In this section, we first show how we connect the link between the model and the survey data and then present sectoral estimates of informality using the model. Finally in the last subsection, we also conduct a policy analysis.

\subsection{Parameters and Data}

We are using the following standard utility function:

$$
U=\frac{\left(c^{\phi_{1}}(\bar{H}-l)^{1-\phi_{2}}\right)^{\phi_{1}}}{\phi_{1}}
$$

The production technology for a formal sector firm is given by

$$
Y_{\text {it }}=A_{i t}\left(k_{i t}^{\alpha} l_{i t}^{1-\alpha}\right)^{\theta}
$$

Next, the technology available to informal firms is: 


$$
Y_{\text {inf }, \text { it }}=A_{i t}\left(l_{\text {inf }, i t}^{1-\gamma}\right)
$$

Moreover, $\lambda(I)$, is chosen to be ${ }^{12}$ the following:

$$
\lambda(l)=\sqrt[n]{l}
$$

Notice that both production functions exhibit decreasing returns to scale technologies to allow for the existence of positive amount of profits in both sectors.

\subsubsection{The Survey}

The survey data that we use in this study contains 1000 representative firms from 16 different sectors and is conducted ${ }^{13}$ in April-May 2012 with financial support from the Scientific and Technological Research Council of Turkey (TUBITAK). Table 1 presents names of these sectors, along with their NACE $\operatorname{codes}^{14}$, as well as the number of firms in each sector. In the design of the survey ${ }^{15}$ to ensure that we have a representative sample of firms across different sectors and regions of Turkey, we targeted the population of firms given by the General Census of Industry and Business Establishments conducted by the Turkish Statistical Institute.

\footnotetext{
${ }^{12}$ This functional form is chosen to have a probability of detection increasing with number of employees and being concave in labor. Several values for $\mathrm{n}$ are experimented and the reported results are using $n=2$. Even though there are some evidence in the literature that firm size and legal enforcement and quality are positively related to each other (Laeven and Woodruff, 2007) the literature is far from establishing a consensus on this. Moreover, we should also mention that the model we use actually has two components for tax enforcement, these are $\rho$ and the function (which is a function of labor) We conduct the comparative static exercises with respect to $\rho$ not and actually, none of our following results change qualitatively if we drop entirely from the analysis. These additional results are available upon request from the corresponding author.

${ }^{13}$ Due to space constraints we do not include the whole survey within the text. Moreover, the survey is originally conducted in Turkish; however the interested reader is invited to contact the corresponding author for an English translation of the survey.

${ }^{14}$ Nomenclature statistique des activités économiques dans la Communauté européenne (In English: Statistical Classification of Economic Activities in the European Community). It is an industry standard classification system used in Europe

${ }^{15}$ Cantekin and Elgin (2016) use the same survey data and provide detailed summary information about the survey as well as some regressions using survey data.
} 
The survey contains more than fifty questions, however, in this study we use only a relatively small subset of them. This subset will serve to the purpose of extracting the necessary parameters for the numerical analysis. These parameters include a productivity/managerial talent level, which will be used to compare the firms' threshold productivity/managerial talent level, capital and labor that the firm uses in production; factor shares, namely $\alpha, \theta$ and $\gamma$; and wages. All these information coming out from the survey will help us to understand whether the firm operates in the formal or informal sector.

In order to be able to use the proposition 1 and classify firms in the formal and the informal sector we proceed as follows: First, we note down the answer to the question where the survey asks the number of employees the firms employs. Multiplying these by the average number of hours a worker works in a year in Turkey (1877 in 2013) gives us the firms' labor sizes. Using the firms' revenues, their purchases of raw material and products as well as rental expenses (The survey specifically asks: "In year 2013, what percentage of your revenue is spent on raw material and product purchases?" and "In year 2013, what percentage of your revenue is spent on rent (building, land and/or machinery)?”) and the average indicator interest rate throughout that year, we calculate the capital stock of each firm. 
Next, in order to calculate the factor shares, we make use of the survey questions that inquire upon firms' expenditures on rent and raw materials, and on wages and social benefits (The survey specifically asks: "In year 2013, what percentage of your revenue is spent on wages, including social benefit spendings?" and "In year 2013, what percentage of your revenue is spent on social benefits for the workers?”). Expenditures on rent and raw materials, as its mentioned in the previous paragraph, represents the investment for physical capital stock; and the sum of the remaining two represents the labor. This allows us to calculate the factors shares, at the firm level, at the sector level as well as at the economy level after aggregation. Finally, in order to make a comparison with the threshold productivity/managerial talent level, we need the productivity level a firm can reach in the formal sector. To do that we use the values of income, capital and labor, factor shares and the equations (7-8) and extract ${ }^{16} A_{i t}$ at the firm-level. If this level is higher than the threshold, then the firm will choose to operate in the formal sector since its productivity/managerial talent will result in higher profits in the formal sector than in

the informal

one. 


\subsubsection{Parameters}

The various parameters that are required for the numerical analysis are chosen based on results of several previous studies. For the parameters in the utility function, we will use the standard values which are $\varphi_{1}=1$ and $\varphi_{2}=0.75 . \beta$, the discount factor is chosen consistent with King and Rebelo (2000), where the authors match the interest rate. The equation they use is a variation of the one below:

$$
r=\frac{1}{\beta}-1
$$

Here, we match an average nominal annual interest rate of $9 \%$ which was the average throughout 2013. The depreciation rate, $\delta$, is chosen to be $0.05^{17}$, following many previous studies. And the total amount of time available for leisure and work, $A$, is normalised to 1 . Informal sector factor share of labor, $\gamma$, and the decreasing to return scale parameter, $\theta$, are calibrated to match the size of the informal sector in Turkey and informal employment (as \% of total non-agricultural employment) in Turkey (both roughly at 30 $\%$ according to Buehn and Schneider (2012) or Elgin and Oztunali, 2012 ${ }^{18}$ ). Surely, one might wonder whether it is appropriate to adopt two different methods to obtain the size of the aggragate informal economy and then deduct the sectoral levels based on this calibration. However, considering the fact that the two aggregate measures we use are originating from the most frequently used methods in the literature, The baseline tax rate $T$ is the current average income tax in Turkey, which is $20 \%$. Enforcement is taken to be zero in the baseline case. Table 2 summarizes the baseline parameter values.

\subsection{Results}

\subsubsection{Benchmark}

After calibration with the previously mentioned baseline parameters, we ob- 


\section{tain the benchmark estimates for each sector presented in Table 3 . As we can observe Table 3, the size of the informal economy varies greatly}

\footnotetext{
$\mathbf{I 7}$ Results are highly robust to the choices of $\mathbf{I}, \mathbf{2}$ and in a range of $\pm 10 \%$ Robustness checks are available upon request from the corresponding author.

18 There are several different methods (with their owns pros and cons) to estimate the economy-wide aggregate size of the informal economy in the literature but the two prevailing with most citations from the literature ones are the ones cited above.
} 
across sectors, even tough the economy-wide level is at its targeted level of $30 \%$. The highest estimates are obtained for sectors I (accommodation and food services), F (construction), E (water supply, sewerage, etc.) and B (mining and quarrying) with $61,46,39$ and $36 \%$ respectively. On the other hand, sectors with lowest informality estimates are $\mathrm{K}$ (information and communication) at $10 \%, \mathrm{~L}$ (real estate activities) at $14 \%$ and $\mathrm{O}$ (education), and $P$ (health and social services), both at $16 \%$. These significant crosssectoral variations justifies our idea of a sectoral analysis and suggest that every sector should be investigated separately when analysing informality tendencies in different sectors.

\subsubsection{Firm Size}

In our study, sectors that have a higher tendency for informality almost consist of small and medium enterprises with low averages of income. As they are mainly small firms, the costs of being formal is greater for them and this naturally results in them being in the informal sector. On the other hand, in the sectors that are highly formal, the ones mentioned in the previous paragraph, the size distribution is much more in favour of larger firms. This is in line with previous findings suggesting that smaller firms (and especially selfemployment businesses) have a higher tendency to be informal. Aiming to 
visualise our findings in this regard, the histograms in Figure 2 illustrate the frequency of firms (informal and formal, respectively) with respect to their revenues, and Figure 3 with respect to their number of employees. These histograms clearly show that informal firms tend to be smaller both in revenue and number of employees. 


\subsubsection{Policy Evaluation}

After obtaining the benchmark estimates of informality in each sector, we now turn to comparative static exercises with respect to policy tools. Specifically, we will focus on two policy tools present in the model: Tax rate and tax enforcement.The benchmark values were set as $T=0.2$ and $\rho=0$.

In the first simulation exercise, we use different values of enforcement while keeping the initial tax rate constant at 0.2. Specifically, we vary the tax enforcement parameter on the informal sector, $\rho$ from o to 0.6 and report the sectoral informality estimates (as \% of total revenue in the sector) in Table 4.

As expected, in all sectors and in the whole economy, as level of tax enforcement increases, informality tendencies decrease At the economy level, an increase in enforcement from o to $10 \%, 10$ to 20 and 20 to $30 \%$ lowers informality about 2, 2 and $3 \%$ respectively. However one needs a $50 \%$ increase in enforcement to halve the informality from 30 to $15 \%$. More importantly, the effect of increasing enforcement is not uniform across sectors. Some sectors such as F (construction) and to some extent P (Human Health and Social Service Activities) respond immediately to increasing enforcement. On the other hand, informality in sector E (Water Supply, Sewerage, Waste Management and Remediation) is not affected by increasing enforcement until the enforcement level is reaches to 0.6. Similarly, sectors, C (Manufacturing) 
D (Electricity, Gas, Steam and Air Conditioning Supply) and I (Accommodation and Food Services) respond quite slowly to increasing enforcement. One policy recommendation one can make given these results can be that enforcement should be directed to sectors responding much faster than the ones which do not.

Next, as a second comparative-statics exercise, we keep the enforcement level constant at its benchmark level of $\rho=0$ and play vary the income tax rate $\tau$ from 10 to $50 \%$, instead of keeping it fixed at $\tau=0.2$. A common result in many papers that investigate the relationship between taxes and informality is that higher taxes push more firms to the informal sector by increasing costs of being formal. Therefore, we expect that increasing the tax rate will increase the level of informality. The results of this exercise are reported in Table 5 .

The first thing we observe in Table 5 is that the effect of varying tax rate is faster than the effect of varying enforcement. Increasing the tax rate from 20 to $50 \%$ more than doubles the aggregate size of the informal sector from 30 to $71 \%$. However, when we reduce the benchmark tax rate from 20 to $10 \%$, the impact on overall informality is almost negligible. (3\%). This also indicates that the marginal effect of the income tax increases with increasing level of taxes. One important result we obtain from this exercise is that while increases in the income tax causes large increases in informality; a reduction is less effective, especially compared to increasing enforcement. 
Moreover, similar to Table 4, we also observe a significant sectoral variation in the response of informality tendencies to changes in taxes. For example, reducing the tax rate from 20 to $10 \%$ does not create any change in 9 sectors; however leads to a very significant reduction (at about $50 \%$ ) in sectors $\mathrm{F}$ and Q. These results again show that an effective tax policy should be designed by taking these differences in sectoral responses into account.

Next, we increase the level of enforcement to 0.95 and vary the tax rate again in the range between 10 to $50 \%$. The results for this exercise are presented in Table 6. Here we that a very high level of enforcement allows for much higher tax rates without increasing informality to high levels. ${ }^{19}$ Furthermore, it is obvious that the combination of stronger enforcement and low taxes seems to be the optimal policy to reduce informality. However, as can be most strikingly seen in the last table, when the level of enforcement is kept at very high levels, the effect of taxation becomes fairly small. This suggests that increased enforcement allows the government to charge the participants in the economy at higher levels of income tax without big ramifications on the account of informality. Of course, this may cause some unseen problems or distortions that are not directly related to informality such as increased

\footnotetext{
19 Deverajan, Jones and Roemer (1989), Ihrig and Moe (2004), de Paula and Scheinkman (2010), Prado (2011) and Slemrod and Glitzer (2013) are other examples obtaining a similar result on the relatively more effective role of enforcement.
} 
unemployment or social unrest.

Finally, we also run two different exercises in which we report the behaviour of aggregate informal sector size, tax revenue and social welfare with varying tax enforcement and tax rate, respectively. To this end, Table 7 presents how these three variables respond to a change in tax enforcement $\rho$. Specifically, we observe from Table 7 that increasing tax enforcement from $o$ to 1 dramatically decreases informal sector size (as \% of the formal economy) and increases the tax revenue. However, social welfare measured by the level of contemporaneous utility decreases in an amount of $0.74 \%$ consumption equivalent.

Table 8 reports results of a similar exercise with fixed $\rho=0$ but varying tax rate $T$. Increasing the tax rate from 0 to 0.50 in increments of 0.05 , dramatically increases informal sector size and reduces social welfare in an amount of $6.56 \%$ consumption equivalent. Tax revenue (maximized at a tax rate of $30 \%$ exhibits a behavior similar to the Laffer Curve and increases up to a certain level and then decreases very rapidly. Accordingly, for a government concerned with societal welfare, reducing taxes seems to be the only tool to 
reduce informal sector size.

The simulation results in Table 7 and 8 indicate that a welfare maximizing government should always choose $\tau=0$ and $\rho=0$, given that the government does not need any tax revenue. However, if we assume that the government should at least collect some revenue to finance an exogenously given (or targeted) amount of government spending or use an exogenously given tax rate (such as $\tau=0.20$ ) then again, a welfare maximizing government should set $\rho$ equal to $o$ and therefore tolerate a relatively larger informal sector. Surely, all these exercises implicitly assume that tax revenue is not used for productive purposes that might positively affect formal output. Obviously, in such a case, a strictly positive $\rho$ or $\tau$ would be optimal.

\subsection{A Further Analysis}

Since the survey data we utilise contains several questions regarding informality perceptions of the interviewees, it allows us to compare our informality estimates against the estimates reported by the survey respondents. In the survey, there are several questions the answers of which can be used as proxies 
for level of informal economic activity. These questions are as follows:

1.Q1: Answers to the direct question in which the participants are asked "In your opinion, what proportion of the value added created in your sector comes from informalactivities?”

2. Q2: Answers to the survey question: "What do you think, is the percentage of employees in your sector working without social security?"

3. Q3: Answers to the survey question: "What percentage of the firms in your sector do no issue (proper) receipts to their customers?”

4. Q4: In Turkey, the average social security spending for a firm is $34.5 \%$ of its total salary spending. The percentage of firms that stay report a ratio below this number can be used as a proxy.

In Table 9 we present the inputed informality measures we obtain using the responses and perceptions of Interviewees (based on these four questions) and compare it with our simulated benchmark estimates. Here we observe that the estimates we construct using our model are not significantly different from the responses and the perceptions of the interviewees. Especially, Q1, which, by construction, is the closest map to our constructed variables (perceived informality as \% of total revenue in the sector) has a very high cross-sectoral correlation (0.98) with our cross-sectoral estimates. Similarly, the correlation with the estimate based on Q2, Q3 and Q4 are $0.89,0.72$ and 0.58 , respectively. This illustrates that our inputed estimates using the dynamic general equilibrium model is in line with the perceived informality measures based on the responses of the interviewees.

\section{Concluding Remarks}

In this study, we used findings from a firm-level survey of the Turkish economy to measure informality in different sectors of the economy as well as evaluated 
different policy tools to reduce it. To this end, we built a two-sector dynamic general equilibrium model and used it along with the firm-level survey to back out sectoral informality size.

Our estimates show that different sectors have different idiosyncratic properties thereby having different levels of informality. Moreover, our comparative statics exercises indicate that at the economy level, enforcement is quite effective in dealing with informality. However, certain sectors are less responsive to changes in enforcement, which suggests that a government focus on the sectors that are sensitive to enforcement could be a beneficial and efficient way to address informality. Income tax, on the other hand, is also effective but at higher levels of enforcement, its effect reduces. Moreover, welfare effects of these tools should also be taken into account as increasing tax enforcement or taxes both reduce social welfare.

Our model is quite standard and is in need of several firm-level data series in order to obtain sectoral estimates of informality. Therefore, it is quite 
straightforward to apply it to other countries using firm-level data from these economies. We leave these applications to future research. 


\section{References}

[1]Acar, E. O. and Aysit Tansel, 2012. "Labor Mobility across the Formal/Informal Divide in Turkey: Evidence from Individual Level Data," IZA Discussion Papers 6271, Institute for the Study of Labor (IZA).

[2]Acar, E. O. and A. Tansel, (2012). "The Formal/Informal Employment Earnings Gap: Evidence from Turkey,” IZA Discussion Papers 6556, Institute for the Study of Labor (IZA).

[3]Acar, E. O. and A. Tansel, (2014). Defining and Measuring Informality in the Turkish Labor Market, IZA Discussion Papers 8377, Institute for the Study of Labor (IZA).

[4]Amaral, Pedro, Quintin, Erwan 2006. A Competitive Model of the Informal Sector.

Journal of Monetary Economics, 53, 1541-1553.

[5]Balkan, B. and S. Tumen. (2014). Firm-Size Wage Gaps along the FormalInformal Divide: Theory and Evidence. Central Bank of Republic of Turkey Working Papers 14-34.

[6]Benjamin, A., Mbaye A.A. 2012.The Informal Sector, Productivity, and Enforcement in West Africa: A Firm-level Analysis. Review of Development Economics. 16 (4), 664-680.

[7]Besley, T., Persson, T. 2013. Chapter 2 ? Taxation and Development, Handbook of Public Economics, Volume 5, 51?110.

[8]Bucheli, M., Ceni, R. 2010. Informality, Sectoral Selection and Earning in Uruguay. Estudios Económicos, 25 (2), 281-307.

[9]Buehn, Andreas; and Friedrich Georg Schneider. 2012. "Shadow economies around the world: novel insights, accepted knowledge, and new estimates". International Tax and Public Finance, 19 (1), 139-171. 
[10]Busso, M., Fazio, M. V., Levy, S. 2012. (In)Formal and (Un)Productive: The Productivity Costs of Excessive Informality in Mexico. IDB Working Paper Series, 341.

[11]Byiers, B. 2009. Informality in Mozambique: Characteristics, Performance and Policy issues USAID memo.

[12]Cantekin, K., Elgin, C. 2016. Extent and Growth Effects of Informality in Turkey: Evidence from a Firm-Level Survey. Forthcoming in Singapore Economic Review. http://dx.doi.org/10.1142/So217590815500794

[13]Cerda, R. A., Saravia, D. 2013. Optimal taxation with heterogeneous firms and informal sector. Journal of Macroeconomics, 35 (C), 39-61.

[14]Dabla-Norris, E., Gradstein, M., Inchauste, G. 2005. What Causes Firms to Hide Output? The Determinants of Informality, IMF Working Paper No. 05/160, IMF,

[15]de Paula, A. and J. A. Scheinkman (2010). Value-added taxes, chain effects, and informality. American Economic Journal: Macroeconomics 2(4), 195?221.

[16]de Paula, A., Scheinkman, J. 2011. The Informal Sector: An Equilibrium Model And Some Empirical Evidence From Brazil. Review of Income and Wealth. 57, 8-26.

[17]Devarajan, S., Jones, C., Roemer, M. 1989. Markets under price controls in partial and general equilibrium. World Development. 17 (12), 18811893.

[18]Djankov, S., Lieberman, I., Mukherjee, J., Nenova, T. 2003. Going Informal: Benefits and Costs?, in B. Belev (ed.), The Informal Economy in the EU Accession 38 Countries: Size, Scope, Trends and Challenges to the Process of EU Enlargement, Sofia: CSD, pp. 63-80. 
[19]Elgin, C. 2012. Vergiler ve Kayitdisi Ekonomi: Bir Degerlendirme ve Turkiye Ornegi, (Taxes and Informal Economy: An Evaluation and Case for Turkey), METU Studies in Development, 39 (2), 237-258.

[20]Elgin, C., Oztunali, O. 2012. Shadow Economies around the World: Model Based Estimates, Working Papers 2012/5, Bogazici University, Department ofEconomics.

[21]Fortin, B., Marceau, N., Savard, L. 1997. Taxation, Wage Controls and the Informal Sector. Journal of Public Economics, 66, 293-312.

[22]Galiani, S., Weinschelbaum, F. 2012. Modeling Informality Formally: Households And Firms. Economic Inquiry. 50 (3), 821-838.

[23]Kaplan, D. S., E. Piedra, Seira, E. 2011. Entry regulation and business start-ups: Evidence from mexico. Journal of Public Economics 95(11), 1501 ? 1515 .

[24]King, R.G., Rebelo, S.T. 2000. Resuscitating Real Business Cycles, RCER Working Papers 467, University of Rochester - Center for Economic Research (RCER).

[25]La Porta, R., Shleifer, A. 2008. The unofficial economy and economic development. Brooking Papers on Economic Activity 105(3), 473?522.

[26]La Porta R., Shleifer, A. 2014. Informality and Development. Journal of Economic Perspectives. 28 (3), 109-126.

[27]Levy, S. 2008. Good Intentions, Bad Outcomes: Social Policy, Informality, and Economic Growth in Mexico. Brookings Institution Press.

[28]Lucas, R. E. 1978. On the Size Distribution of Business Firms. Bell Journal of Economics. 9 (2), 508-523. 
[29]Ihrig, J., Moe, K. 2004. Lurking in the shadows: The informal sector and government policy. Journal of Development Economics. 73, 541-577.

[30]Maloney, W. F. 1999. Does Informality Imply Segmentation in Urban Labor Markets? Evidence from Sectoral Transitions in Mexico. World Bank Economic Review, 13 (2), 275-302

[31]OECD 2008., Declaring Work or Staying Underground: Informal Employment in Seven OECD Countries, in OECD Employment Outlook 2008.

[32]Perry, G.E., Maloney, W.F., Arias, O.S., Fajnzylber, R., Mason, A.D., Saavedra-Chanduvi, J. 2007. Informality: Exit and Exclusion, Washington, DC: World Bank.

[33]Pisani, M. J., Pagan, J. A. 2004. Sectoral Selection and Informality: a Nicaraguan Case Study. Review of Development Economics, 8, 541?556.

[34]Prado, M. 2011. Government policy in the formal and informal sectors. European Economic Review 55, 1120?1136.

[35]Rauch, J. E. 1991. Modelling the informal sector formally. Journal of Development Economics. 35, 33-47.

[36]Savasan, F., Schneider, F. 2006. What Determines Informal Hiring? Evidence from the Turkish Textile Sector", Middle East Business and Economic Review, 18 (2), 14-32.

[37]Schneider, F., Enste, D. 2000. Shadow Economies: Size, Causes and Consequences. Journal of Economic Literature. 38, 77-114.

[38]Schneider, Friedrich 2005. Shadow economies around the world: what do we really know? European Journal of Political Economy 21(3), 598 ?642. 
[39]Slemrod, J., Glitzer, C. 2013. Tax Systems. MIT Press. 
[40]Tansel, Aysit 1999. Formal Versus Informal Sector Choice of Wage Earners and their Wages in Turkey, Working Papers 9927, Economic Research Forum, revised Sep 1999.

[41]Tansel, Aysit 2001. Wage Earners, Self Employed and Gender in the Infor- mal Sector in Turkey, Working Papers 0102, Economic Research Forum, revised Jan 2001.

[42]Taymaz, Erol. 2009. Informality and Productivity: Productivity Differen- tials between Formal and Informal Firms in Turkey, ERC Working Papers 0901, ERC - Economic Research Center, Middle East Technical Univer- sity. 